\title{
Editorial: Let there be Finesse
}

'Have you read all these books?' A suspicion generated by the number and variety of the volumes is reinforced by handling the clean pages and jackets. The defence may take a number of different forms. Sometimes a book is perfectly readable but is not ripe to serve the purposes of a particular reader. Sometimes the explanation that is needed is that what is in question is not a book-or at any rate not of the simple paradigm that the host and the guest may think of in their conversation. The cabbie's A to $Z$ street guide is not readable. A picture book may have few and slight captions, and little or no text. Works of reference are a sub-class containing internal differences: the Encyclopaedia Britannica has quite a different structure from that of the Greek Dictionary. I may be reading an item in the Encyclopaedia or the Dictionary but it is not altogether natural to say that we are reading the Encyclopaedia; and less natural still to speak of reading a Dictionary.

Oddly, we do speak of reading maps, though maps and books of maps are further away from the simple paradigm than is reading music and reading of minds.

We travel further from the paradigm when we speak of reading the book of nature. On a smaller scale we may find the aspiration of a child to read the whole of the Bible from alpha to omega. Is he reading, or just passing his eyes over some words in print?

At dinner one evening I happened to remark that I am a slow reader, and conjectured that my classical upbringing was partly responsible. My neighbour, an engineer, said he had never heard a more severe condemnation of any course of study. He was thinking of information-which is not what it is most appropriate to think of when assessing a literary or linguistic or historical education. What $I$ had in mind was the slow savouring that absorbs poetry or philosophy, or any other text that may be difficult for any number of reasons. Not long ago Mr Martin Warner shed light on some of these processes when he wrote about finesse in philosophy.

There is also the phenomenon of opposition, at least from the time of Heraclitus. What is good is also bad: peace and war, one and many, good and evil. The reading and understanding of symbols in any language or medium is liable to an endemic slowness.

The French painter François Jousselin and some of his friends call themselves metaphysical painters. They allow themselves and others-whether painters or not-to describe in words their 


\section{Editorial}

Heraclitean oppositions. The key that imprisons is also the key that liberates. An intriguing example we have not drawn from the metaphysical painters: think of the many modes of application of oil. It is one thing to lubricate and another to anoint, or to pour oil on troubled waters, or on a salad bowl or a salad.

Philosophers have denounced the use of ocular images, and the users of such images are unable to resist what they are committed to renouncing. And why not? We may fittingly employ such pictures, and note the breadth and depth of them, and say, in suitable cases, 'there's glory for you'. Above these foothills rise the peaks of the ranges. Let there be light. Let your light so shine before men that they may see your good works and glorify your Father which is in heaven. 